\title{
Doctor Zhivago, Rusia entre dos \\ mundos: elaboración de un sono-libro, un recurso docente innovador
}

Doctor Zhivago, Russia between two worlds: development of sono-book, an innovative teaching resource

MARTA VELA GONZÁLEZ 
$\Rightarrow$ Recibido 10/10/2018

$\checkmark$ Aceptado 07/01/2019

\section{Resumen}

Este artículo pretende reflexionar sobre la fusión de música y literatura con fines docentes, desde una perspectiva puramente radiofónica, es decir, sin imágenes asociadas. A través de un nuevo género, el sono-libro, ofrecemos una nueva perspectiva de la novela de Boris Pasternak, El doctor Zhivago -con el precedente de su soberbia adaptación cinematográfica por David Lean-, desde la contextualización de una selección de textos de la novela, recitados por actores, con la música contemporánea al autor de la novela, ofreciendo así un completo friso estético, inspirado por la novela, pero enriquecido, a su vez, por una selección musical históricamente propicia.

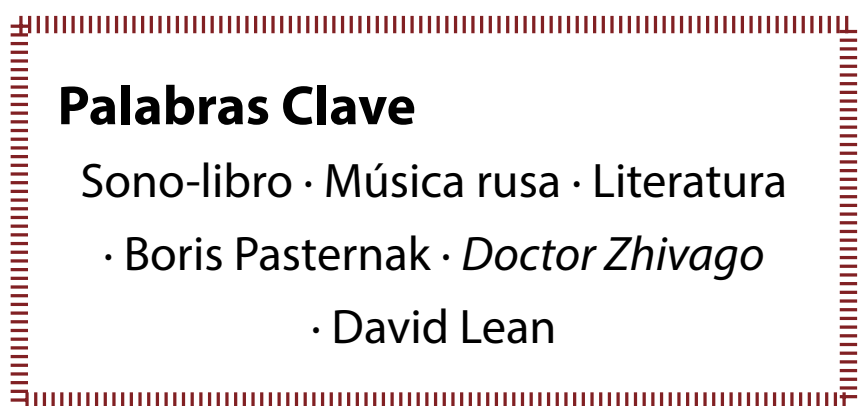

\section{Abstract}

This article aims to reflect on the fusion of music and literature for teaching purposes, from a purely radiophonic perspective, that is, without associated images. Through a new genre, the sono-book, we offer a new perspective on the novel by Boris Pasternak, Doctor Zhivago - with the precedent of his superb cinematographic adaptation by David Lean-, from the contextualization of a selection of texts from the novel, recited by actors, with contemporary music to the author of the novel, thus offering a complete aesthetic frieze, inspired by the novel, but enriched, in turn, by a historically favorable musical selection.

\section{Keywords}

Sono-book - Russian music . Literatura $\cdot$ Boris Pasternak - Doctor Zhivago $\cdot$ David Lean 


\section{Arte y entretenimiento: una mirada actual}

La perenne aceleración vital que sufrimos en el mundo occidental de la actualidad ha influido, como no podía ser de otra manera, en el ámbito del arte y del entretenimiento, o, más bien, en la relación entre ambos términos, antaño indisolublemente unidos, hoy día, cada vez más alejados uno del otro, a causa de la irrupción, desde hace décadas, de la sociedad de consumo y de la necesidad intrínseca de éste de someter a cualquier producto a un rápido proceso de obsolescencia que permite la aparición, publicidad y venta (y nueva obsolescencia) del siguiente.

Esta frivolidad, basada en lo efímero y sustentada por la venta, propiciada, a su vez, por la industria, que ha afectado al ámbito del arte y al de la cultura a nivel mundial, ha sido definida por Mario Vargas Llosa como la civilización del espectáculo, sustituyendo, así, en las últimas décadas, a la idea tradicional de cultura por una serie de productos low cost, que han destruido, en muchos casos, la relación entre arte y entretenimiento:
La diferencia esencial entre aqueIla cultura del pasado y el entretenimiento de hoy es que los productos de aquélla pretendían trascender el tiempo presente, durar, seguir vivos en las generaciones futuras, en tanto que los productos de éste son fabricados para ser consumidos al instante y desaparecer, como los bizcochos o el popcorn. Tolstói, Thomas Mann, todavía Joyce y Faulkner escribían libros que pretendían derrotar a la muerte, sobrevivir a sus autores, seguir atrayendo y fascinando lectores en los tiempos futuros. Las telenovelas brasileñas y las películas de Bollywood, como los conciertos de Shakira, no pretenden durar más que el tiempo de su presentación, y desaparecer para dejar el espacio a otros productos igualmente exitosos y efímeros. La cultura es diversión y lo que no es divertido no es cultura (...) Para esta nueva cultura son esenciales la producción industrial masiva y el éxito comercial. La distinción entre precio y valor se ha eclipsado y ambas cosas son ahora una sola, en la que el primero ha absorbido y anulado al segundo. Lo que tiene éxito y se vende es bueno y lo que fracasa y no conquista 
al público es malo. El único valor es el comercial. La desaparición de la vieja cultura implicó la desaparición del viejo concepto de valor. El único valor existente es ahora el que fija el mercado (Vargas Llosa, 2012:10).

La presencia de este valor puramente comercial en el ámbito de la cultura la somete, diariamente, a una constante devaluación, sobre todo, a nivel técnico y moral, lo que nos ha conducido no sólo a la mayor crisis financiera conocida desde el crack de 1929, sino, también, a lo que Emilio Lledó ha calificado como una crisis de inteligencia ${ }^{1}$.

La obra de arte -otrora, ente espiritual e inmaterial de incalculable valor- se ha convertido también en un producto que se comercializa igual que un coche, un detergente o una película, con un envoltorio vistoso y una insistente campaña publicitaria, lo cual no asegura, en absoluto, el avance de la expresión artística, sino que, por contra, responde a un fin meramente monetario: vender un producto que, aun falso, sea asequible, tanto económica como espiritualmente, a una gran parte del mercado de consumo. De hecho, la 1 http://diariodeavisos.elespanol. com/2013/11/emilio-Iledo-la-verdadera-crisis-es-inteligencia/ necesidad de ampliar este mercado de venta exige una constante simplificación de los contenidos del producto, de ahí que, progresivamente, la industria haya intentado adaptar la obra de arte al gusto del cliente, circunstancia que, lógicamente, la ha empobrecido.

Hoy, sin embargo, la música se ha convertido en un mero ornamento, para guarecer noches vacías con visitas a óperas y conciertos, para realizar actos festivos públicos, o también, a través de la radio, para disipar o a avivar el silencio de la soledad del hogar. Así, se da el caso paradójico de que aunque en la actualidad tenemos cuantitativamente mucha más música en cualquier época anterior -incluso casi, permanentemente- ésta no significa nada en nuestras vidas: ¡un pequeño y agradable adorno! (Harnoncourt, 2006:7).

De esta manera, como en muchos otros ámbitos, ha nacido un arte de tipo ligth, heredero de la llamada cultura de masas de la segunda mitad del siglo XX, que en el campo de la música se ha traducido en interpretación estandarizada (Vela, 2018), $y$ en otra suerte de fenómenos devaluadores: 
No es por eso extraño que la literatura más representativa de nuestra época sea la literatura light, leve, ligera, fácil, una literatura que sin el menor rubor se propone ante todo y sobre todo (y casi exclusivamente) divertir. Atención, no condeno ni mucho menos a los autores de esa literatura entretenida pues hay, entre ellos, pese a la levedad de sus textos, verdaderos talentos. Si en nuestra época es raro que se emprendan aventuras literarias tan osadas como las de Joyce, Virginia Woolf, Rilke o Borges no es solamente en razón de los escritores; lo es, también, porque la cultura en la que vivimos inmersos no propicia, más bien desalienta, esos esfuerzos denodados que culminan en obras que exigen del lector una concentración intelectual casi tan intensa como la que las hizo posibles. La literatura light, como el cine light y el arte light, da la impresión cómoda al lector y al espectador de ser culto, revolucionario, moderno, y de estar a la vanguardia, con un mínimo esfuerzo intelectual. De este modo, esa cultura que se pretende avanzada y rupturista, en verdad propaga el conformismo a través de sus manifestaciones peores: la complacencia y la autosatisfacción (Vargas Llosa, 2012:11).

Tal vez sea hora de recuperar el verdadero sentido del arte y su función espiritual, al margen del entretenimiento, diversificado hoy día en una multiplicidad de variedades -sobre todo, relacionadas con la imagen-, a partir de los valores de la llamada vieja cultural, desde la perspectiva de la música, la literatura e, incluso, la radio.

\section{Música y literatura}

La unión de música y literatura ha tenido una larga y exitosa trayectoria artística desde los orígenes de la cultura occidental, sobre todo, desde su prodigioso desarrollo durante la antigüedad grecolatina. El texto, fundamentalmente, religioso, durante la época del canto llano y la de las primeras polifonías, fue un pilar imprescindible en la música de la Edad Media $y$, justo en el momento del surgimiento del género instrumental, a finales del siglo XVI, que auguraba el declive de la música vocal, apareció la ópera -definida por Kühn (2003:116) como "uno de los más bellos errores creativos de la historia 
de la composición: hacia 1600 se buscaba el modo de recitación del drama antiguo ero se alcanzó el canto monódico"-, el primer intento de fusión entre música y literatura que alcanzaría su culminación a finales del siglo XIX con la Gesamkunstwerk wagneriana.

Así pues, música y literatura se retroalimentan, precisamente porque su unión denota, en la mayoría de ocasiones, la suma de estructuras determinadas por el estilo, es decir, por las mismas coordenadas histórico-estéticas:

Es urgente volver a las fuentes de la cultura. El primer deber de un intérprete es ubicar la obra en su época. Porque el estilo está definido ya desde el principio, de forma muy general, evidentemente, por el contexto cultural en el que se inserta la obra (...) El estilo está, pues, constituido por aquellos que se translucen de la personalidad del compositor -o, más aún que de su su propia personalidad- de su forma de captar el mundo y transponerlo. $Y$ esto sucede en la misma época $y$, a menudo, en los mismos países o en países muy próximos. La importancia de los países o de ciertas ciudades ha sido considerable del nacimiento de muchos estilos (Deschausées, 2009: 36).

De esta forma, la obra de arte de cualquier época debe tener un significado histórico, que remita al momento en que fue creado, y otro contemporáneo, que permita contextualizar el valor artístico de la misma en las circunstancias del receptor, de ahí que, en efecto, la alianza entre música y literatura resulte muy productiva en ambas perspectivas:

Toda gran obra del pasado tiene dos significados, uno de carácter contemporáneo y otro histórico. $\mathrm{Si}$ un poema, una pintura o una pieza musical no tienen significado contemporáneo, sólo pertenecen a la historia e interesarán principalmente al erudito. Cuando nos acercamos a una obra como el Paraíso perdido de Milton, el Juicio Final de Miguel Ángel o la Pasión según San Mateo, de Bach, nos olvidamos completamente de la historia, pues se establece una comunicación directa con nosotros en términos relativos a nuestros propios sentimientos $y$ pensamientos. En otros términos, tiene significado contemporáneo (...) y no es que estas obras no ten- 
gan significado histórico, pues están cargadas de dicho significado, pero nadie dirá que podemos comprenderlas con mayor claridad cuando sólo hayamos comprendido sus implicaciones históricas. Pero la verdad es que la historia del arte se vuelve importante para el hombre sólo después de que el mismo arte ha despertado su interés e implicado, por lo menos, de forma parcial, sus sentimientos (Moore, 1990:3).

De hecho, la literatura ha sido una fuente de inspiración permanente para la música instrumental, como se demuestra en tendencias tales como la música programática o la Gesamkunstwerk, al margen, por otro lado, de los que ejercen diariamente el oficio de la interpretación musical y su docencia:

¿Recuerda el pasaje en modo menor del segundo movimiento de Hammerklavier? Es Abraham llevando a Isaac a la montaña y usando el cuchillo sobre su cabeza... ¿Y la fuga? Es la construcción del arca, ¿qué otra cosa podría ser? Kokoschka me dibujó mientras yo reproducía esa construcción del arca (Richter citado en Borísov, 2015:26).
Oborin era una persona de una educación amplísima, uno de los profesores más sabios y cultivados que se podía encontrar en el Conservatorio de Moscú de aquellos años. Siempre resultaba muy interesante hablar con él de los temas más variados relacionados con la música, la literatura y el arte, y en sus clases empleaba constantemente todo tipo de asociaciones para subrayar sus puntos de vista. Oborin solía decir que le aburría la compañía de los pianistas, y prefería socializar con sus colegas compositores, entre los que se incluía Shostakovitch (Berman, 2010:14).

Incluso, la unión de música y poesía implica determinados códigos compartidos que nos remiten a procesos altamente simbólicos (Gómez Redondo, 1994), muy alejados, por tanto, del lenguaje cotidiano:

Bajo la condición previa de que un músico se esfuerce por conseguir la reproducción adecuada y el sentimiento de una obra maestra, podría decirse, apoyándonos en un poema de Friedrich Rückert procedente de la Sabiduría del Brahmán y que re- 
cuerdo de mi juventud: "ihay tanto sentido oculto en la obra!» (Mantel, 2010: 28).

Con la elaboración del sono-libro, o libro sonoro, pretendemos ofrecer una nueva recreación de la fructífera unión entre música y literatura, contextualizando algunos extractos recitados de la obra literaria original con una selección musical de la misma época, cuyo resultado, ajeno al mundo de la imagen, mantiene, eso sí, un íntimo parentesco con el desaparecido género de la radio-novela, relatado magistralmente por Vargas Llosa (2006) en su inolvidable libro La tía Julia y el escribidor.

\section{Método: el sono-libro o libro sonoro}

Para la elaboración del sono-libro titulado Doctor Zhivago: Rusia entre dos mundos se eligió el texto de El doctor Zhivago (1957) en el centésimo aniversario de la Revolución rusa (1917) y del Tratado de Brest-Litovk (1918) con el objetivo de ofrecer una perspectiva diferente a la mostrada por David Lean en su adaptación cinematográfica de 1965 -rodada casi en su totalidad en España-. No debe olvidarse que, más allá de la historia de amor narrada gracias al inolvidable trabajo de Omar Sharif y Julie Christie, la novela se constituye como un canto a la libertad de conciencia individual, a través del poeta protagonista, un trasunto del propio Pasternak, quien no consigue renunciar a sus ideas por adaptarse a los tiempos y paga el precio de la traición con su familia, con su amor y, en su suma, con su vida. De hecho, El doctor Zhivago fue prohibida por el régimen soviético y Pasternak renunció al Premio Nobel concedido en el año 1958.

Para de reducir una novela de 752 páginas en su última edición en español (Galaxia Gutemberg, 2016) a una hora de programa radiofónico, se llevó a cabo un análisis pormenorizado de la estructura de la novela en dos sentidos, a saber, las grandes áreas temáticas contempladas en la obra, por un lado, y la organización narrativa del autor, por el otro, marcada por los cuatro encuentros entre la pareja protagonista, la intrahistoria (Unamuno, 1905) acaecida tras una serie de acontecimientos que abarcan todo el período revolucionario en Rusia, desde 1905, hasta el final de la Segunda Guerra Mundial, donde finaliza la novela $y$, curiosamente, comienza el filme de Lean, que utiliza una estructura retrospectiva. 
A continuación, podemos observar los hechos históricos narrados en la obra y la vida intrahistórica de los protagonistas:

- 1904-1905: Guerra ruso-japonesa

- Diciembre 1905: Revolución de 1905

- Julio 1914: Guerra contra Alemania

- Marzo 1917: abdicación del Zar

- Octubre 1917: Bolcheviques al poder

- Diciembre 1917: Guerra civil rusa

- Marzo 1918: Tratado de Brest - Litosvk

- Julio 1918: asesinato de la familia imperial

- Octubre 1918: creación de la Unión Soviética

- 1921: hambruna

- Marzo 1921: inicio de la NEP

- 1922: Stalin como secretario general del PCE

- Julio 1924: muerte de Lenin

- 1929: fin de la NEP

$-1930 \ldots$ hambrunas, represión, purgas

- Septiembre de 1939: Pacto de no agresión, invasión de Polonia

- 1941: Operación Barbarroja

- 1945: fin de la Segunda Guerra Mundial
Mme. Guichard en Moscú

Yuri ve a la Lara por primera vez

Yuri y Lara en el frente

Yuri en Moscú; Lara en Yuriatin

Los Zhivago en Varikino

Yuri, partisano

Yuri y Lara en Yuriatin - Varíkino

Figura 1: cronología de acontecimientos en El doctor Zhivago

De esta manera, podemos observar la hábil trama narrativa planteada por Pásternak sobre la densa red de acontecimientos creada por la combinación historia e intrahistoria, marcada, a su vez, por los cuatro encuentros de los protagonistas enunciados a continuación: el primero ocurre en el frente, en el hospital fronterizo de Meliuzéyev -nombre inventado-; el segundo, en la biblioteca de Yuriatin, que inicia la relación amorosa de los personajes; el tercero, de nuevo en Yuriatin y Varíkino -la propiedad campestre de los Gromeko a las afueras de la ciudad, tras la deserción de Yuri-; el último, finalmente, en Moscú, en la capilla ardiente del doctor, adonde Lara acude a despedirse (téngase en cuenta que se ha considerado encuentro ${ }^{2}$ la situación de interacción

2 Precisamente, uno de los poemas recogidos al final de la novela trata el encuentro de los protago- 
entre los dos protagonistas; antes de la guerra, Yuri y Lara habían coincidido dos veces en Moscú, en la casa de su madre, Mme. Guichard, cuando ésta intenta suicidarse, y en una fiesta de Navidad, donde Lara trata de disparar sobre Komarovsky).

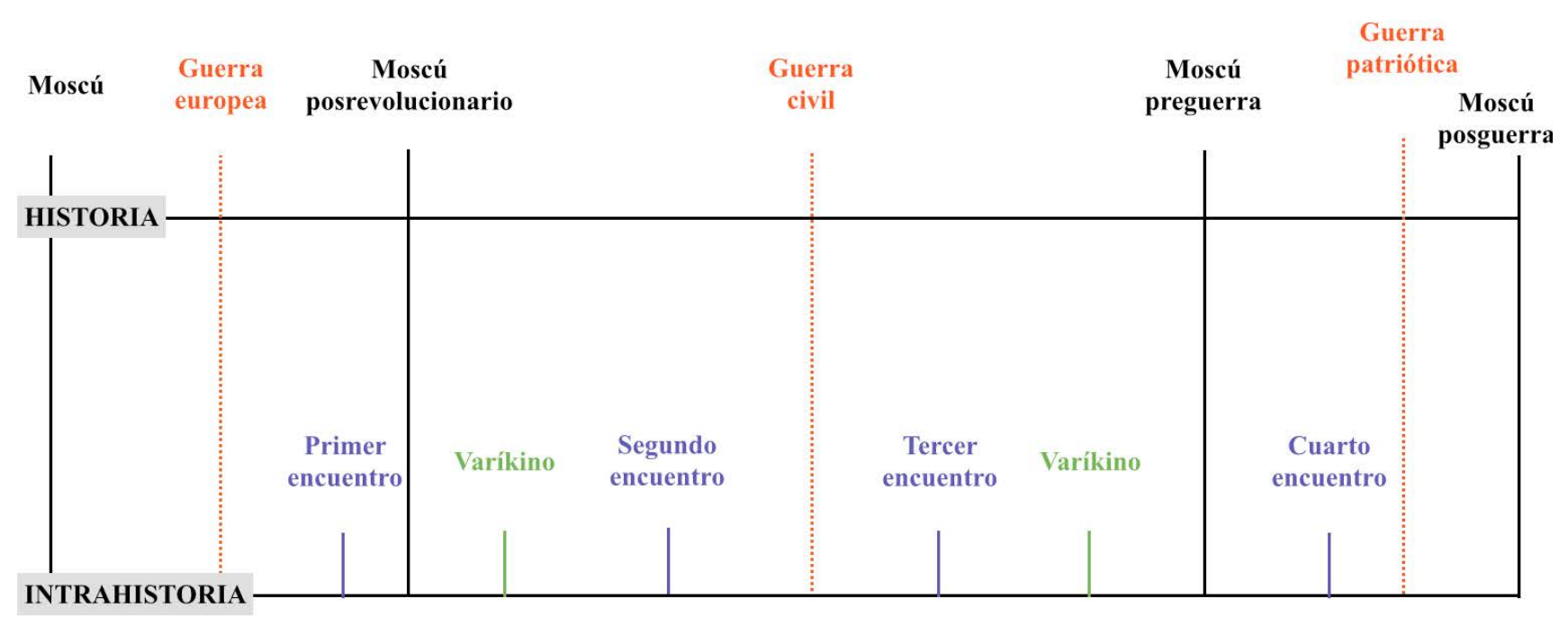

Figura 2: historia e intrahistoria en El doctor Zhivago

Las principales áreas temáticas de la novela se resumen en cuatro: la primera, el amor, pero, sobre todo, el adulterio, encarnada por la pareja protagonista, al que se suman Tonya Gromeko, la esposa de Yuri, y Pavel Antípov, el esposo de Lara (convertido, más tarde, en el fanático revolucionario Strélnikov); la segunda, la violencia, referida a los acontecimientos históricos del momento, sobre todo, la Revolución de 1905, la Guerra Europea, la Revolución de 1917, la Guerra civil rusa, la creación de la Unión Soviética, las purgas de los años de entreguerras, finalmente, la Segunda Guerra Mundial; la dicotomía entre el campo y la ciudad es la tercera, con el contraste entre Moscú, plagada de miserias, hambrunas y epidemias -adonde Yuri regresa derrotado para morir, una vez ha perdido a Lara para siempre- y Varíkino, la propiedad campestre de los Gromeko, donde los personajes parecen escapar, temporalmente, por supuesto, de la violencia urbana y el desabastecimiento de productos básicos; finalmente, en cuarto lugar, se observa un último tema principal, la esperanza a través del arte, simbolizada en el libro de poemas de Zhivago, publicados, supuestamente, años después de la muerte del poeta, que se adjuntan al final de la novela.

nistas en Yuriatin, con idéntico título. 


\section{Doctor Zhivago}

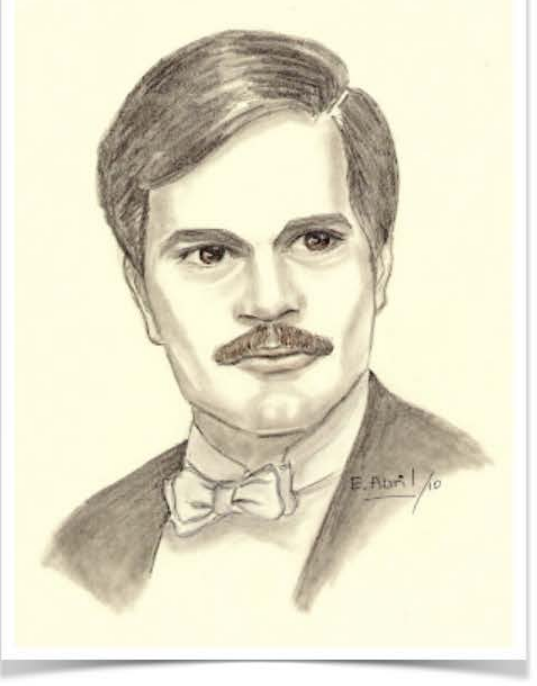

\section{amor (adulterio) violencia campo-ciudad esperanza a través del arte}

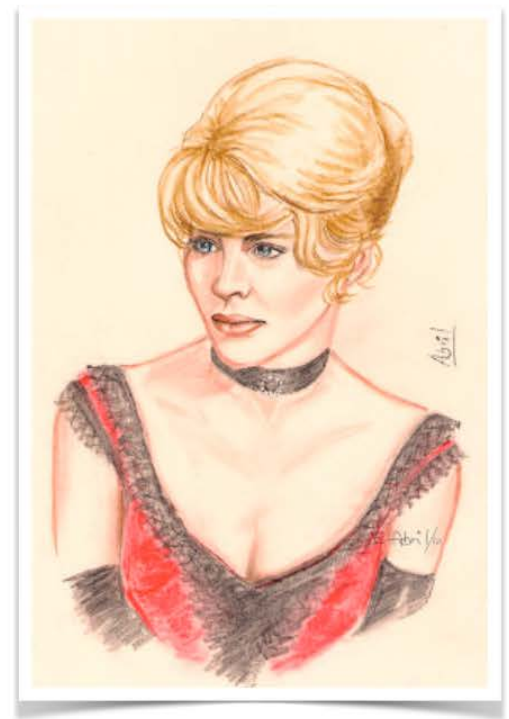

Figura 3: áreas temáticas en El doctor Zhivago.

Imágenes de http://elapartamento-enparis.blogspot.com

En función de esta organización temático-narrativa, se eligieron los fragmentos musicales con el interés de realzar los grandes temas de la novela a través de los textos seleccionados, de este modo, la selección musical alude a la segunda parte del título del programa Rusia entre dos mundos, presentando dos esferas enfrentadas, el zarismo del siglo XIX y el bolchevismo del XX, que se traducen en dos polos estéticos igualmente contrastantes, a saber, la estética romántica de compositores como Tchaikovsky, Rachmaninov o Scriabin, deudores de la música europea de la primera mitad del siglo XIX, frente a la ambivalencia estilística de los compositores soviéticos, como Prokofiev, Shostakovitch o Khatchaturiam, obligados, por circunstancias políticas, a la estética socialista, como en Gloria a Stalin (1949) de Shostakovitch, o seguidores, en otras ocasiones, del lenguaje romántico de sus predecesores, como en el Adagio del ballet Spartacus (1956) de Khatchaturiam. A estos fragmentos se añadieron, como colofón del programa, dos números de la banda sonora original de la película, compuesta por Maurice Jarre (1965), el Tema de Lara y el Café de estudiantes.

Así pues, los temas principales de la novela propician la selección musical del programa, nutrida íntegramente de compositores rusos de los siglos XIX y XX, con una única excepción, la de la Sonata Op. 47 "Kreutzer" de Beethoven, que alude a las ve- 
ladas musicales de las clases moscovitas acomodadas antes de la guerra, a la que pertenecen los parientes de Yuri, los Gromeko, retratadas magistralmente por TóIstoi en su novela homónima, La sonata a Kreutzer (1889), cuyo tema central reside, de nuevo, en el adulterio.

Así, pues en función de los cuatro temas predominantes, encontramos ejemplos de música referida a la burguesía urbana de Moscú (Beethoven: Sonata a Kreutzer; Tchaikovsky: Vals de El lago de los cisnes) y a la imagen bucólica del campo (Stravinsky: Cuatro canciones campesinas para trompa y voces femeninas); música relacionada con el régimen soviético y la violencia de la guerra (Shostakovitch: Allegretto de la Sinfonía "Leningrado", Gloria a Stalin, Sinfonía "Revolución"; Degeyter, Internacional socialista; Prokofiev, Concierto para piano y orquesta $n \circ 5$, segundo movimiento, Alla marcia); música relativa a la historia de amor entre los protagonistas (Tchaikovsky: Francesca da Riminiy Romeo y Julieta, ambas obras basadas, junto al Spartacus de Khatchaturiam, en un amor imposible; Rachmaninov, Variaciones sobre un tema de Paganini, variación XVIII; Prokofiev, tercer movimiento del Concierto para piano y orquesta $\mathrm{n} \circ 5$, Lento) $\mathrm{y}$, por último, un fragmento dedicado a la descripción de la creación artística, representado por la Sonata para piano $\mathrm{n}{ }^{\circ} 4 \mathrm{de}$ Scriabin.

La muerte (o desaparición) de Lara, fuera de la película de Lean, que finaliza con el infarto de Zhivago, se narra mediante con el propio texto de Pasternak -y el Adagio lamentoso de la Sexta Sinfonía de Tchaikovsky-, que alude, veladamente, al gulag de la década de los años treinta:

Una vez, Lara salió de casa y no volvió más. Al parecer, fue detenida en la calle. Murió o desapareció quién sabe dónde, olvidada bajo un número sin nombre de una lista que se perdió más tarde, en uno de aquellos innumerables campos de concentración comunes o femeninos del norte (Pasternak, 2010:670).

Merece mención a parte el primer fragmento musical utilizado, perteneciente al primer movimiento, Moderato, del Concierto $n \circ 2$ para piano y orquesta de Rachmaninov, cuyo inicio recuerda al sonido de la campana, tan importante en la tradición ortodoxa rusa, contextualizado con el entierro de la madre de Yuri, que abre la novela. 
A continuación, se ofrece un cuadro-resumen con la selección musical del programa y el reparto de fragmentos musicales según las áreas temáticas del texto:

\begin{tabular}{|c|c|c|c|}
\hline RACHMANINOV & Concierto $n^{\circ} 2 \mathrm{Op} .18$, Moderato & KHATCHATURIAM & Spartacus, Adagio \\
\hline BEETHOVEN & Sonata "Kreutzer", Adagio sostenuto & PROKOFIEV & Concierto $n^{\circ} 5$, Lento \\
\hline TCHAIKOVSKY & Vals del Lago de los cisnes & SHOSTAKOVITCH & Gloria a Stalin \\
\hline SHOSTAKOVITCH & Allegretto, Sinfonia "Leningrado" & KHATCHATURIAM & Spartacus, Adagio \\
\hline TCHAIKOVSKY & Francesca da Rimini & SHOSTAKOVITCH & Sinfonía IV, "Revolución" \\
\hline RACHMANINOV & Variaciones Paganini (var. XVIII) & SCRIABIN & Sonata $n^{\circ} 4$ \\
\hline DEGEYTER & Internacional socialista & TCHAIKOVSKY & Romeo y Julieta \\
\hline STRAVINSKY & Cuatro cantos campesinos & TCHAIKOVSKY & Francesca da Rimini \\
\hline TCHAIKOVSKY & Romeo y Julieta & TCHAIKOVSKY & Sinfonía VI, Adagio lamentoso \\
\hline PROKOFIEV & Concierto $n^{\circ} 5$, Alla marcia & JARRE & Café de estudiantes \\
\hline & & JARRE & Tema de Lara \\
\hline
\end{tabular}

Figura 4: selección musical en Doctor Zhivago: Rusia entre dos mundos

Por último, queremos aludir al tema que cierra la novela de Pasternak, la esperanza a través del arte, íntimamente relacionado el tema de la creación artística, que aparece en múltiples ocasiones, dado que, en buena parte, se trata de una historia autobiográfica, que el médico-poeta es un trasunto del propio autor. De hecho, El doctor Zhivago presenta un claro ejemplo de intertextualidad, donde se combina el texto novelado de Pasternak, junto a los poemas escritos por Yuri Zhivago, publicados a su muerte, después de la Segunda Guerra Mundial, cuya génesis se explica en el devenir de la trama, sobre todo, en aquellos dedicados al leitmotif principal de la novela, la vela que arde expuesta a las inclemencias exteriores, so pena de apagarse, como la vida humana.

Para el programa se seleccionaron, entonces, tres de los veinticinco poemas agregados por el autor al final de la novela, Marzo, Encuentro y Una noche de invierno; a continuación, Pasternak explica el proceso de creación sobre éste último, durante una de las veladas heladas en Varíkino, en torno a un estribillo constantemente repetido: so- 
bre la mesa ardía una vela/una vela ardía.

Entonces, con el inmenso torrente de un río que con su movimiento tornea las piedras del fondo y hace girar las ruedas de los molinos, el propio flujo del discurso, con la fuerza de sus leyes, crea en su camino, de paso, el metro y la rima, y otras mil formas y figuras,aún más importantes, pero desconocidas hasta ese momento, inexploradas, sin nombre. En aquellos minutos, Yuri sentía que no era él quien ejecutaba la parte esencial del trabajo, sino algo que lo superaba, que se encontraba por encima de él y lo guiaba (Pasternak, 2010:587).

Precisamente, la novela termina con la esperanza suscitada en los amigos de Zhivago, Gordon y Dúdorov, por su libro de poemas, publicados al final de la Guerra patriótica -el nombre de la Segunda Guerra Mundial en Rusia-, pese a la idea de que la dictadura socialista duraría mucho más allá del enfrentamiento con la Alemania nazi, incluso, más allá de la muerte de Stalin.
Aunque la victoria no había traído la luz ni la libertad que esperaban para después de la guerra, como habían pensado, el presagio de la libertad flotaba, no obstante, en el aire durante los años de posguerra y constituía su único contenido histórico (...) y era como si el pequeño libro, [el de la poesía de Zhivago], entre sus manos supiese todo esto y diese a sus sentimientos apoyo y confirmación (Pasternak, 2010:689690).

De esta forma, tras la muerte de Lara, el Adagio lamentoso de la Sexta Sinfonía de Tchaikovsky pone fin a esta historia narrada a través de la radio, cerrando así uno de los períodos más convulsos de la historia europea del siglo XX, narrado por Boris Pasternak.

\section{Resultados: un experimento en Radio Clásica}

A continuación, ofrecemos un cuadro-resumen que incluye los acontecimientos históricos e intrahistóricos de la novela, las cuatro áreas temáticas fundamentales, los fragmentos musicales escuchados -los más relevantes para la histo- 
ria- y la trayectoria creadora de Zhivago a lo largo de la obra, con la lectura de los tres poemas escogidos.

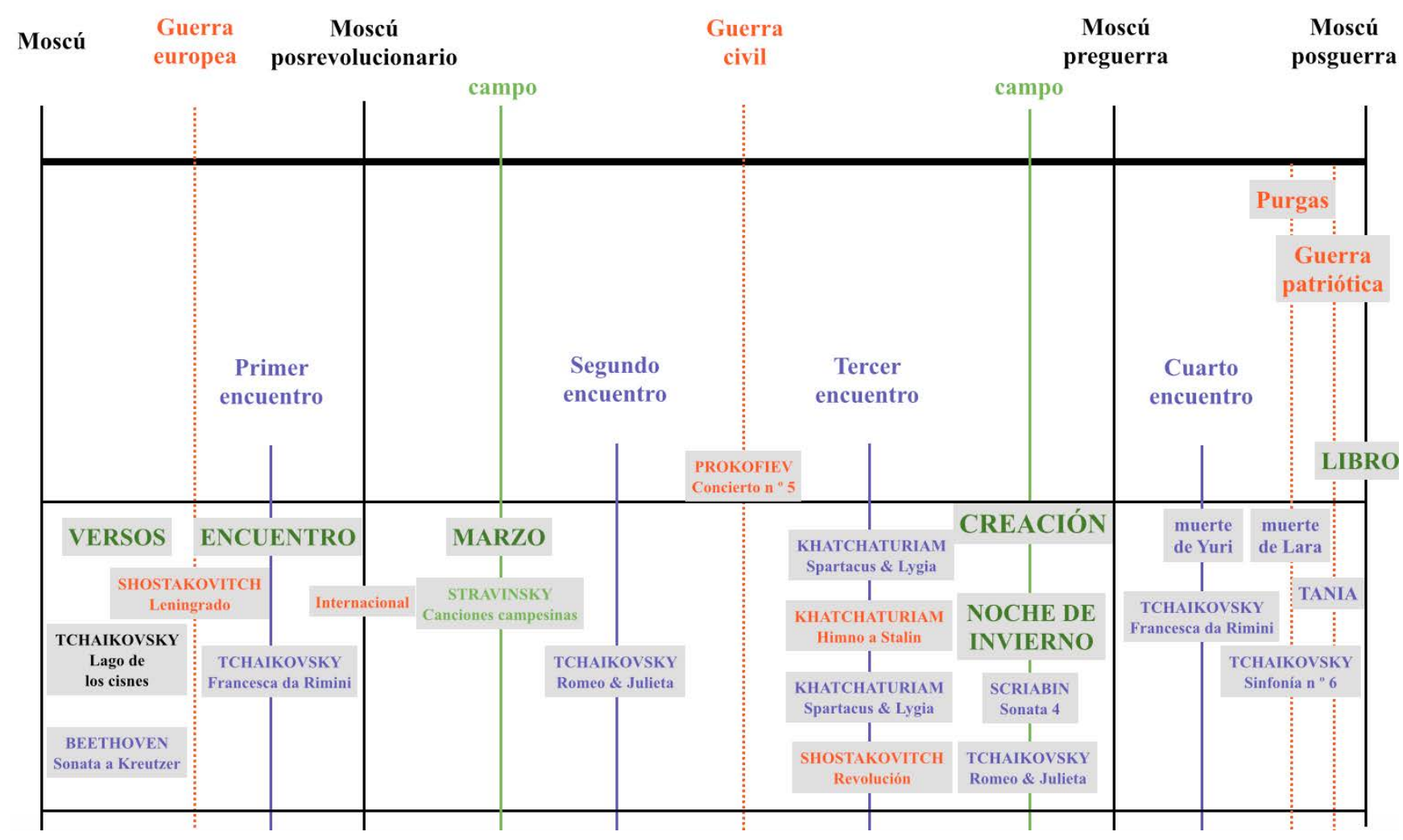

Figura 5: estructura en Doctor Zhivago: Rusia entre dos mundos

Para la elaboración del sono-libro titulado Doctor Zhivago: Rusia entre dos mundos, junto a la emisión de la selección musical mencionada, se seleccionaron dos recitadores que dieran vida a los textos de Pasternak, en este caso, los colaboradores del programa Jorge Nicolás, como Yuri, y Carmen Herrera, como Lara. 


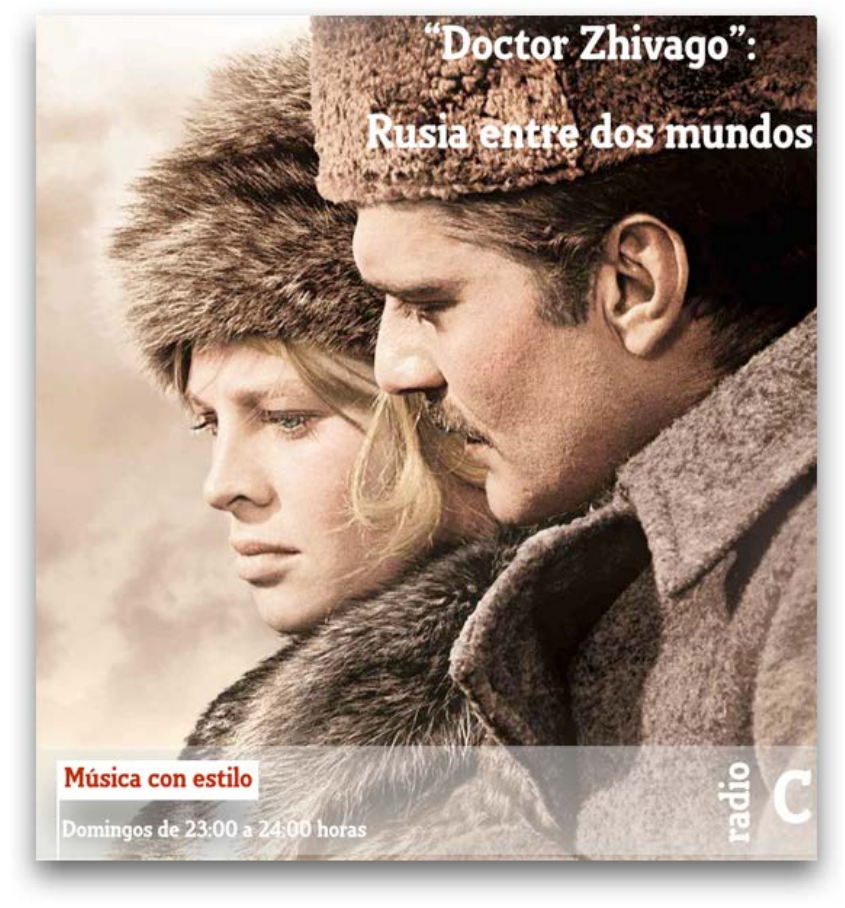

Figura 6: Doctor Zhivago, Rusia entre dos mundos, banner publicitario

A continuación, ofrecemos un enlace donde puede escucharse $y / o$ descargarse el programa completo a partir del sistema de podcasts de Radio Nacional de España: http://www.rtve.es/alacarta/ audios/musica-con-estilo/musica-estilo-doctor-zhivago-rusia-entre-dos-mundos-30-09-18/4764718/

\section{Conclusiones}

Con el sono-libro Doctor Zhivago: Rusia entre dos mundos hemos querido recrear la novela de Pasternak de manera diferente a lo mostrado por Lean en su filme de 1965 y por otras versiones recientes, a través de un canal radiofónico, sin imagen alguna, como reto frente al contexto, eminentemente visual, que nos rodea en la actualidad.

A partir de este experimento se va a llevar a cabo un proyecto de animación a la lectura y a la escucha de música académica, contextualizadas en su ámbito histórico-estético correspondiente, dado que la aplicación más inmediata del sono-libro puede consistir en completar, por un lado, la amplia formación cultural que todo artista debe poseer $y$, por el otro, en animar al profano a iniciarse en el mundo de artes combinadas mediante un programa ameno, de gran contenido histórico y estético.

Por tanto, nunca es demasiado pronto para empezar a enseñar a las nuevas generaciones de intérpretes musicales una sabiduría completa sobre la voluntad artística inherente a los distintos estilos históricos, completada con la referencia al estilo personal, aquellas particularidades de estructuración que son autóctonas de la individualidad de un maestro y que nacen de su reacción personal hacia su época (Swarowsky, 1989:10). 
Los directores de orquesta, los cantantes, los pianistas, todos los virtuosos deberían saber o recordar que la primera condición que debe cumplir quien aspire al prestigioso nombre de intérprete es ante todo la de ser un ejecutante sin falta. El secreto de la perfección reside, ante todo, en la conciencia de la ley que una obra impone a quien la ejecuta. Y henos aquí de nuevo en el gran tema de la sumisión que hemos evocado tan a menudo durante estas lecciones. Esta sumisión exige una flexibilidad que a su vez requiere, con la maestría técnica, el sentido de la tradición y, por encima de todo, una cultura aristocrática que no es fácil de adquirir (Stravinsky, 2006:114).

De esta forma, a pesar de nuestro mundo actual, lleno de ruido mediático y cultura ligth, queremos animar al lector y al oyente a fusionar, de nuevo, arte y entretenimiento, los valores de la vieja cultura, a través de estos ideales, anteriormente enunciados por dos referentes de la música académica del siglo XX, de sabiduría completa (Stravinsky) y cultura aristocrática (Swarowsky), que tratamos de inspirar a través del nuevo género radiofónico del sono-libro.

\section{Referencias}

Berman, B. (2010). Notas desde la banqueta de un pianista. Barcelona: Boileau.

Borísov, Y. (2015). Por el camino de Richter. Barcelona: Acantilado.

Deschausées, M. (2009). El intérprete y la música. Madrid: Rialp.

Gómez Redondo, F. (1994). El lenguaje literario. Madrid: Edaf.

Harnoncourt, N. (2006). La música como discurso sonoro. Barcelona: Acantilado. 
Kühn, C. (2003). Historia de la composición musical en ejemplos comentados. Cornellà de Llobregat: Idea Books.

Mantel, G. (2010). Interpretación. Del texto al sonido. Madrid: Alianza.

Moore, D. (1990). Guía de los estilos musicales. Madrid: Taurus.

Pasternak, B. (2010). Doctor Zhivago. Madrid: Galaxia Gutemberg

Unamuno, M. (1905). En torno al casticismo. Biblioteca Virtual Miguel de Cervantes. http://www.cervantesvirtual.com/obra-visor/en-torno-al-casticismo-253798/html/dcc55a76-2dc6-11e2-b417-000475f5bda5_5.html\#I_0_

Stravinsky, I. (2006). Poética musical. Barcelona: Acantilado.

Swarowsky, H. (1989). Defensa de la obra. Madrid: Real Musical.

Vargas Llosa, M. (2012). La civilización del espectáculo. Madrid: Alfaguara.

Vargas Llosa, M. (2006). La tía Julia y el escribidor. Madrid: Punto de lectura.

Vela, M. (2018). “Fenómenos actuales en la enseñanza de la interpretación: interpretación estandarizada, neo-diletanttismo... y una propuesta didáctica". Revista Artseduca, número 21, septiembre de 2018, pp. 34-57. 